\title{
Sunlight- driven photocatalytic hydrogen production from water using metal-doped Strontium Titanate perovskite
}

\author{
Pushkal Sharma $^{a}$, Cheng-Ting Lee ${ }^{b}$, Jeffrey Chi-Sheng Wu ${ }^{\text {b,* }}$ \\ ${ }^{a}$ Department of Chemical Engineering, Indian Institute of Technology Roorkee, Uttarakhand, \\ 247667, India
}

${ }^{\mathrm{b}}$ Department of Chemical Engineering, National Taiwan University, Taipei, 10617, Taiwan

*Corresponding author: +886-2-2363-1994, cswu@ntu.edu.tw

\begin{abstract}
:
The effects of various metal dopants on the photocatalytic water splitting activity of $\mathrm{SrTiO}_{3}$ based photocatalysts were investigated using experimental studies. The $\mathrm{SrTiO}_{3}: \mathrm{Rh}(1 \%)$ has been found to give the best efficiency in water splitting out of the various metal-doped samples studied. However, the same host doped with other metal dopants such as Fe, V, Ga, and Sb leads to negligible $\mathrm{H}_{2}$ evolution even when at least $\mathrm{Fe}$ has a better visible light response. Our results accompanied by previously conducted theoretical studies by our group explain the high photocatalytic water splitting activity of $\mathrm{Rh}$ doped $\mathrm{SrTiO}_{3}$. Furthermore, the effects of the amount of catalyst, the proportion of sacrificial agent and $\mathrm{pH}$ were studied for the $\mathrm{SrTiO}_{3}: \mathrm{Rh}$ (1 mol\%) along with studying its activity with seawater.
\end{abstract}

\section{Introduction:}

The efficient use of solar energy to synthesize fuels is believed to be an efficient solution to energy and environmental issues we are currently facing. Interest in renewable fuels for energy production is growing rapidly and $\mathrm{H}_{2}$ is identified as a source of ultimate clean energy. It is used in chemical industries, for example, in industrial ammonia synthesis. Current production relies on steam reforming of hydrocarbons, which are mainly obtained from fossil fuels. Such reactions are not only energy-intensive but also release greenhouse gases. Thus, driven by the current growing concern about global climate change, efforts have been made to develop new alternative and environmentally friendly energy sources, such as the photocatalytic production of hydrogen from natural resources such as water and solar energy because they are abundant, renewable and have a better impact on the environment compared to fossil fuels. Fujishima and 
Honda ${ }^{1}$ discovered that water could be decomposed under UV light using a $\mathrm{TiO}_{2}$ electrode by the generation of electrons and holes where the water is oxidized by the holes to generate $\mathrm{O}_{2}$ and $\mathrm{H}^{+}$, while the free electrons reduce $\mathrm{H}^{+}$to produce $\mathrm{H}_{2}$ on the cathode. To initiate such a reaction, the highest level of the valence band should be more positive than the water oxidation level (1.23 V vs NHE), while the lowest level of the conduction band should be more negative than hydrogen evolution potential $(0 \mathrm{~V}$ vs $\mathrm{NHE})$. However, $\mathrm{TiO}_{2}$ does not absorb visible light and now a lot of research focuses on developing new materials having visible light absorption ability. The $\mathrm{ABO}_{3}$ type perovskite strontium titanate $\left(\mathrm{SrTiO}_{3}\right)$ is one of the promising photocatalyst, which matches this requirement. The wide bandgap $(3.3 \mathrm{eV})$ of this photocatalyst results in a less than $5 \%$ sunlight absorption and low evolution efficiency ${ }^{2}$. Substituting some metal ions with dopants introduces extra band positions forming new energy levels near CB and VB resulting in the reduced minimum light absorption energy gap. Attempts have been made to dope particulate $\mathrm{SrTiO}_{3}$ with noble metals such as $\mathrm{Rh}, \mathrm{Pd}, \mathrm{Ir}, \mathrm{Ru}, \mathrm{Mn}$ and Pt for enhancing the photocatalytic activity ${ }^{3,4}$. However, many correlated factors ${ }^{5}$ such as the recombination of active electrons, structural defects of the crystal and energy barrier at surface reaction site make the designing of high-performance photocatalyst, a confounding task.

\section{Experiments:}

A closed batch photoreactor was used to perform the hydrogen evolution reaction, which was used offline with a gas chromatograph (GC). A $300 \mathrm{~W}$ Xe lamp with AM 1.5 filter was used as a light source to mimic visible light. A certain amount of photocatalyst was dispersed in water (with methanol as a sacrificial agent) using magnetic stirrer in the Pyrex glass photoreactor. During all the experiments, helium was used to purge the reactor to expel any remaining gases inside before initiating the reaction. The gas samples were taken periodically and analyzed with a Younglin Instruments GC (molecular sieve 5 A column, PDHID detector with He carrier). Doped $\mathrm{SrTiO}_{3}$ was prepared by mixing $\mathrm{SrCO}_{3}$ (Aldrich, 99\%), $\mathrm{TiO}_{2}$ (Aldrich, 99.5\%) and respective metal oxides: $\mathrm{Rh}_{2} \mathrm{O}_{3}, \mathrm{Sb}_{2} \mathrm{O}_{3}, \mathrm{Ga}_{2} \mathrm{O}_{3}, \mathrm{~V}_{2} \mathrm{O}_{5}$ and $\mathrm{Fe}_{2} \mathrm{O}_{3}$ according to the composition of $\mathrm{SrTiO}_{3}: \mathrm{M}(1 \mathrm{~mol} \%)$ and then calcining the mixture in air at $1273 \mathrm{~K}$ for $10 \mathrm{~h}$. The photocatalysts synthesized were confirmed from XRD and were further characterized by UV visible spectroscopy. For the seawater splitting experiments, the seawater was obtained from the Tamsui River in Taiwan and the anion concentration in seawater as measured by Ion Chromatography (IC) machine equipped with a conductivity detector and IonPac AS4A-SC (4 X $250 \mathrm{~mm}$ ) column. Standard IC solutions of $\mathrm{Cl}^{-}, \mathrm{Br}^{-}$, and $\mathrm{SO}_{4}{ }^{2-}$ ions were prepared to make the anion calibration lines. 


\section{Results and Discussion:}

XRD showing no extra diffraction lines from other crystal phases confirmed the successful introduction of dopants to $\mathrm{SrTiO}_{3}$ perovskites slab. UV visible spectrum confirms the better visible light response of $\mathrm{SrTiO}_{3}$ : Fe than $\mathrm{SrTiO}_{3}: \mathrm{Rh}$.

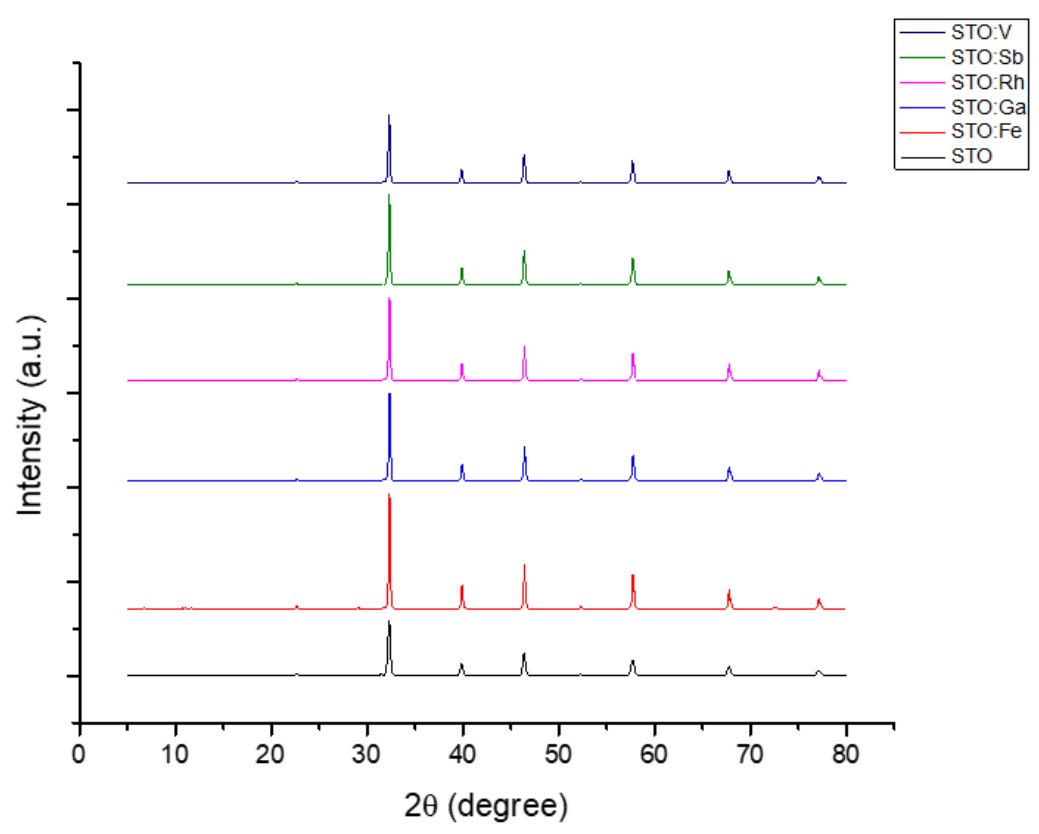

Figure 1: XRD patterns of $\mathrm{SrTiO}_{3}: \mathrm{M}(1 \%), \mathrm{M}=\mathrm{V}, \mathrm{Sb}, \mathrm{Rh}, \mathrm{Ga}, \mathrm{Fe}$, and pristine $\mathrm{SrTiO}_{3}$

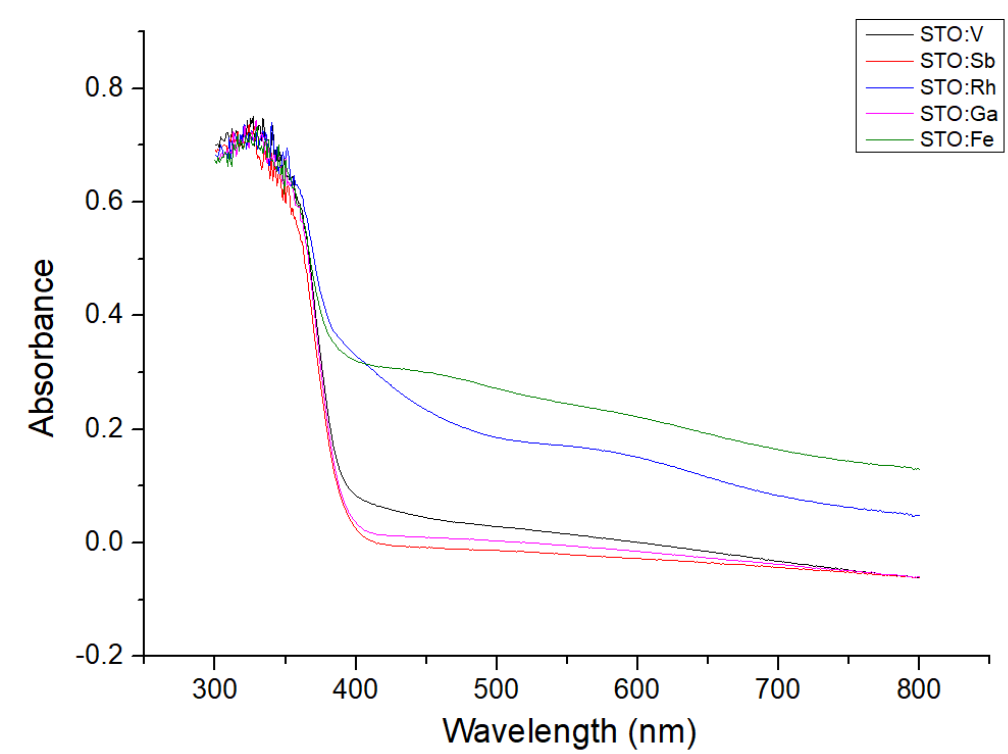

Figure 2: UV visible spectrum of SrTiO3: $\mathrm{M}(1 \%), \mathrm{M}=\mathrm{V}, \mathrm{Sb}, \mathrm{Rh}, \mathrm{Ga}$, and $\mathrm{Fe}$ from $300 \mathrm{~nm}$ to $800 \mathrm{~nm}$ 
The hydrogen evolution of $\mathrm{SrTiO}_{3}: \mathrm{M}(1 \mathrm{~mol} \%)$ was confirmed by gas chromatography as described before for the batch photoreactor with $0.1 \mathrm{~g}$ catalyst dispersed in $100 \mathrm{~mL}$ water with $10 \mathrm{~mL} \mathrm{MeOH}$ (i.e. $9 \%$ by volume methanol solution). In addition to the aforementioned dopants, $\mathrm{Li}$ and $\mathrm{Gd}$ were also included. The outstanding photocatalytic activity of $\mathrm{Rh}$ doped $\mathrm{SrTiO}_{3}$ may be explained by the suitable position of the dopant energy levels as shown by first principle DFT calculations by our group ${ }^{6}$. In $\mathrm{Rh}$ doped $\mathrm{SrTiO}_{3}$, the dopant energy level is slightly above VB and therefore the excitation energy threshold is a bit lower. After the excitation, the vacant dopant states can become a recombination center for electrons in $\mathrm{CB}$. The nearness of the $\mathrm{Rh}$ dopant states to VB allows a fast replenishment of electron by absorbing either thermal vibration of lattice or low energy photons. For Fe, perhaps the new dopant states are near the middle of the bandgap, away from the VB edge that prevents the replenishment of electrons via lattice thermal vibration. Thus, it needs to be refilled by absorbing new photons and thus giving a longer lifespan to Fe recombination centers. Another possibility might be that the higher Fe states compared to $\mathrm{Rh}$ states make them much closer to $\mathrm{O}_{2} / \mathrm{H}_{2} \mathrm{O}$ oxidation potential and thus implying a smaller driving force for oxidation.

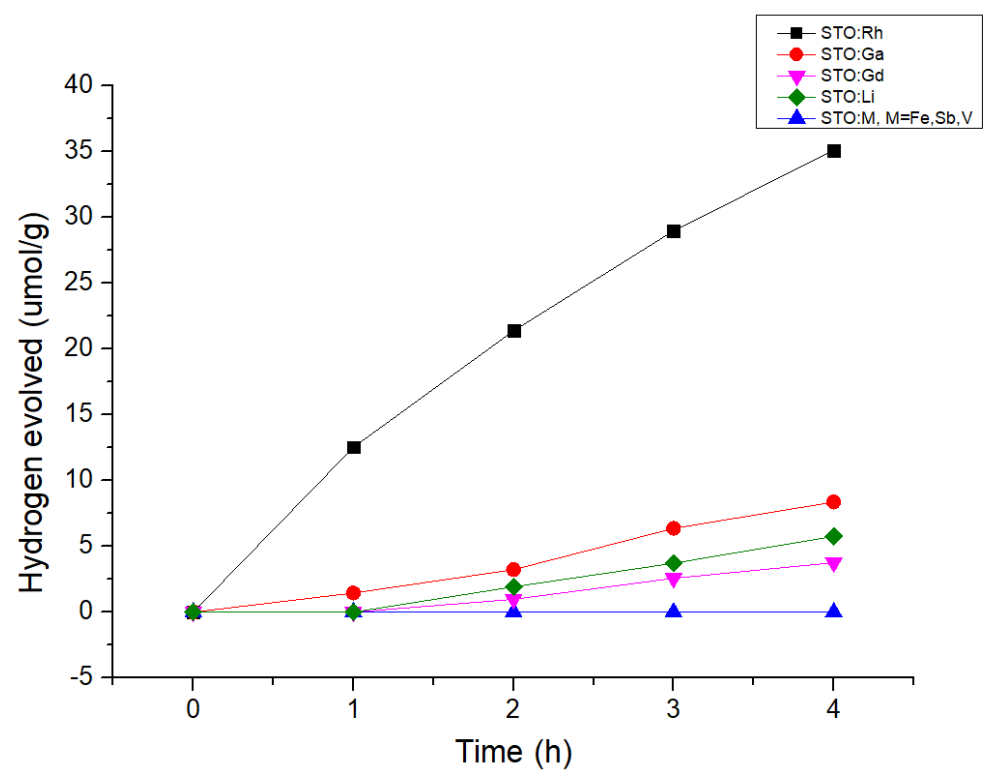

Figure 3: Photocatalytic water splitting activity of $\mathrm{SrTiO}_{3}: \mathrm{M}(1 \mathrm{~mol} \%), 0.1 \mathrm{~g}$ catalyst dispersed in $100 \mathrm{~mL}$ water and $10 \mathrm{~mL}$ methanol under $300 \mathrm{~W}$ Xe lamp light source 


\section{Influence of reaction parameters:}

Since $\mathrm{SrTiO}_{3}$ doped with $\mathrm{Rh}$ showed more promising results, we studied the influence of various reaction parameters for the photocatalytic water splitting activity for the same photocatalyst. Increasing the amount of catalyst will increase the amount of light absorbed by the semiconductor particles and thus the hydrogen production; however, eventually, a point will be reached where the entire incident visible light will be absorbed and rate cannot be increased further. Increasing the amount of catalyst further will reduce the penetration depth of the light irradiation due to loss of scattered light to the exterior, and thus reducing the hydrogen evolution. The next parameter to be tested was the volume of the sacrificial agent methanol. As the concentration of the methanol increases, the number of recombination is reduced, but at the same time the water molecules, which give hydrogen after going reduction decreases and thus these two opposing mechanisms, lead to an optimum volume. The third parameter to be examined was the $\mathrm{pH}$ of the reactant solution whose influence on the rate of $\mathrm{H}_{2}$ evolution was investigated by the addition of $\mathrm{HCl}$ and $\mathrm{NaOH}$. The $\mathrm{pH}$ of the solution can directly affect the stability of the photocatalyst as well as the redox processes of water reduction and oxidation. It was observed that at acidic $\mathrm{pH}$, the hydrogen evolution substantially increased which is due to increased adsorption of $\mathrm{H}^{+}$on the semiconductor surface, and thus increasing the possibility of reduction of $\mathrm{H}^{+}$to $\mathrm{H}_{2}$ by free electrons.

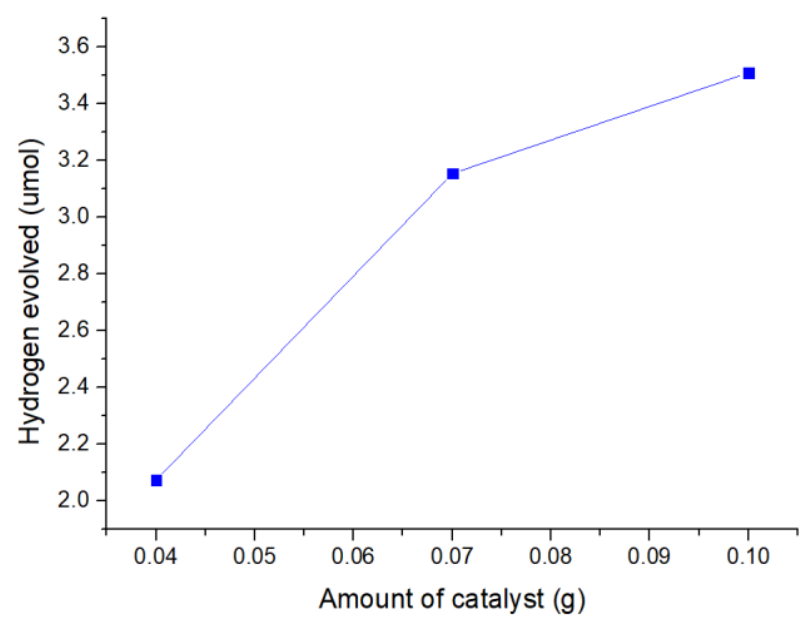

Figure 4: Photocatalytic water splitting activity of $\mathrm{SrTiO}_{3}: \mathrm{Rh}(1 \mathrm{~mol} \%)$ with varying amount of catalyst in $100 \mathrm{~mL}$ water and $10 \mathrm{~mL} \mathrm{MeOH}$ under $300 \mathrm{~W}$ Xe lamp light source after 4 hours 


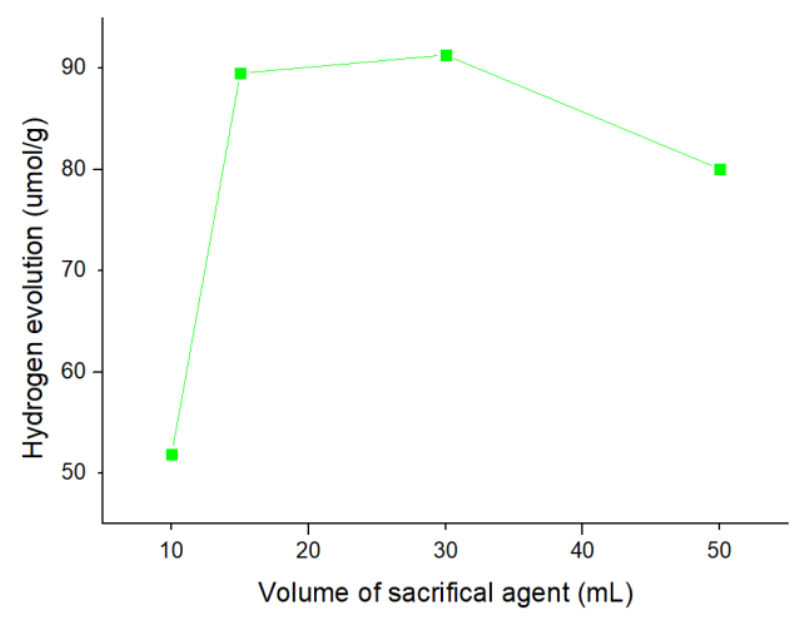

Figure 5: Photocatalytic water splitting activity of $0.04 \mathrm{~g} \mathrm{SrTiO}_{3}: \mathrm{Rh}(1 \mathrm{~mol} \%)$ with the varying volume of $\mathrm{MeOH}$ in $100 \mathrm{~mL}$ water under $300 \mathrm{~W}$ Xe lamp light source after 4 hours

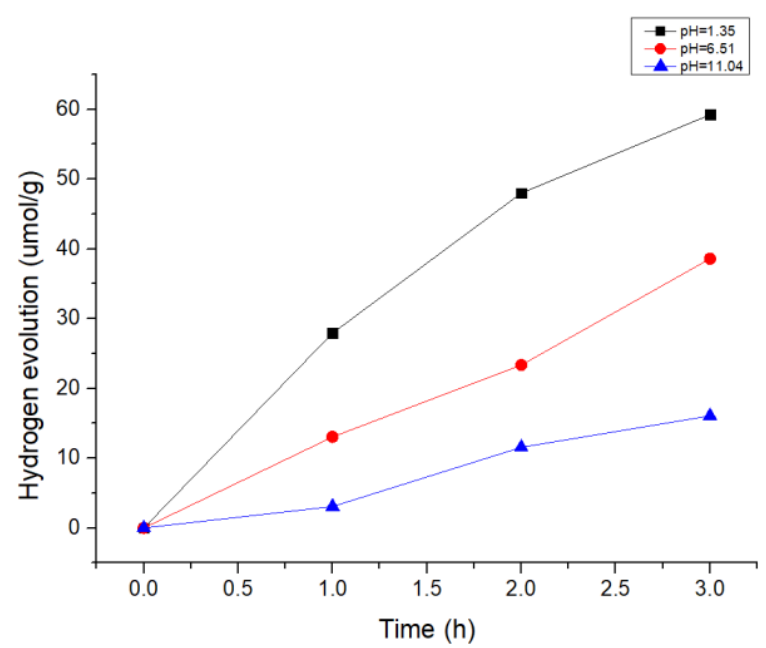

Figure 6: Photocatalytic water splitting activity of $0.04 \mathrm{~g} \mathrm{SrTiO}_{3}: \mathrm{Rh}(1 \mathrm{~mol} \%)$ with varying pH in $100 \mathrm{~mL}$ water and $10 \mathrm{~mL} \mathrm{MeOH}$ under $300 \mathrm{~W}$ Xe lamp light source

\section{Photocatalytic hydrogen evolution from seawater}

Since the most promising source of water for photocatalysis in the future could be seawater; we conducted studies on the possible use of direct water from the sea for the water-splitting experiments. Another reason for using the seawater was that the abundant chlorine ions present in the seawater can act as a hole scavenger ${ }^{7}$. The seawater was analyzed by ion chromatography and the results are shown in Figure 8. The hydrogen evolution rates are comparatively very small as compared to distilled water used in prior experiments and thus further investigations are needed to evaluate the viability of using seawater directly. 


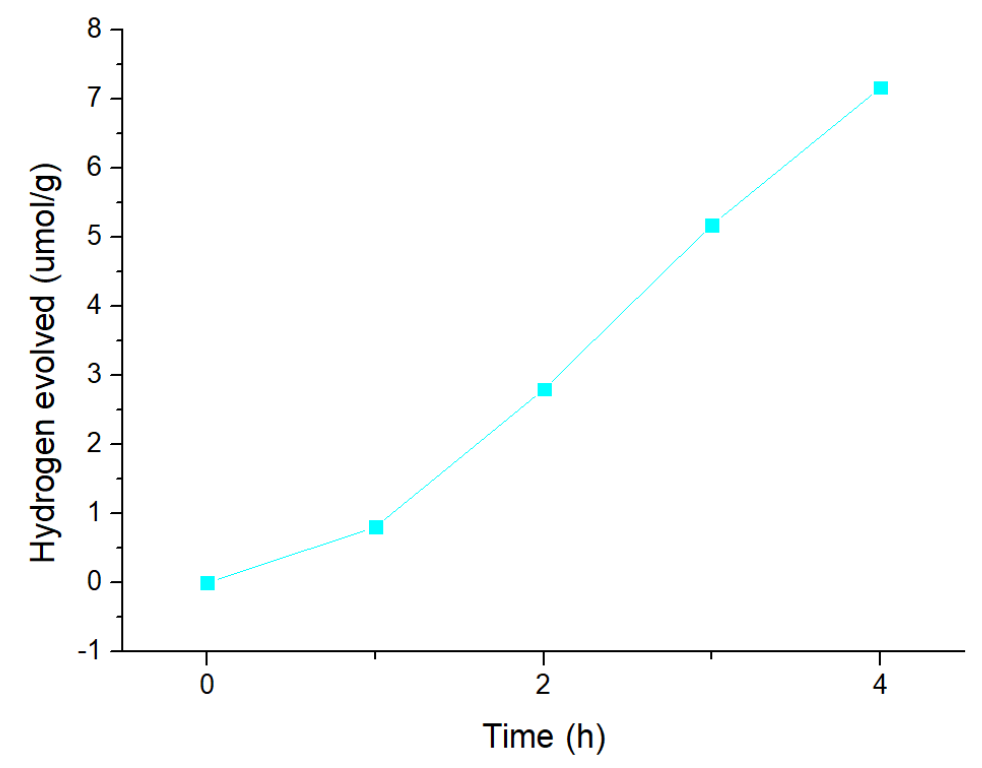

Figure 7: Photocatalytic water splitting activity of $\mathrm{SrTiO}_{3}: \mathrm{M}(1 \mathrm{~mol} \%), 0.015 \mathrm{~g}$ catalyst dispersed in $100 \mathrm{~mL}$ water under $300 \mathrm{~W}$ Xe lamp light source

\begin{tabular}{|ll|l|l|l|}
\hline & $\mathrm{Cl}^{-}$ & $\mathrm{Br}^{-}$ & $\mathbf{S O}^{2-4}$ \\
\hline $\begin{array}{l}\text { Concentration } \\
\text { ppm) }\end{array}$ & (in & 2237.6 & 5.7674 & 288.32 \\
\hline
\end{tabular}

Figure 8 Characterisation of seawater used for water splitting experiment

\section{Conclusion:}

The $\mathrm{Rh}$ doped $\mathrm{SrTiO}_{3}$ exhibits the best $\mathrm{H}_{2}$ evolution efficiency among the various doped photocatalyst studied. The proximity of the dopant Rh energy states to valence band maximum allows efficient electron replenishment and reduce the trapping of electrons from CB. Further many factors need to be considered to further optimize the hydrogen evolution from $\mathrm{SrTiO}_{3}$ and several factors such as the intensity of light irradiation, temperature, type of sacrificial agent and pressure need to be examined. Moreover, the use of seawater directly for water splitting needs further attention.

\section{References:}

1. Fujishima, A. and Honda, K., 1972. Electrochemical photolysis of water at a semiconductor electrode. Nature, 238(5358), p.37. 
2. Takizawa, M., Maekawa, K., Wadati, H., Yoshida, T., Fujimori, A., Kumigashira, H. and Oshima, M., 2009. Angle-resolved photoemission study of Nb-doped SrTiO 3. Physical Review B, 79(11), p.113103.

3. Konta, R., Ishii, T., Kato, H. and Kudo, A., 2004. Photocatalytic activities of noble metal ion doped $\mathrm{SrTiO}_{3}$ under visible light irradiation. The Journal of Physical Chemistry B, 108(26), pp.8992-8995.

4. Bae, S.W., Borse, P.H. and Lee, J.S., 2008. Dopant dependent band gap tailoring of hydrothermally prepared cubic $\mathrm{SrTi}_{x} \mathrm{M}_{1-x} \mathrm{O}_{3}(\mathrm{M}=\mathrm{Ru}, \mathrm{Rh}, \mathrm{Ir}, \mathrm{Pt}, \mathrm{Pd})$ nanoparticles as visible light photocatalysts. Applied Physics Letters, 92(10), p.104107.

5. Navarro Yerga, R.M., Alvarez Galvan, M.C., Del Valle, F., Villoria de la Mano, J.A. and Fierro, J.L., 2009. Water splitting on semiconductor catalysts under visible-light irradiation. ChemSusChem: Chemistry \& Sustainability Energy \& Materials, 2(6), pp.471-485.

6. Chen, H.C., Huang, C.W., Wu, J.C. and Lin, S.T., 2012. Theoretical investigation of the metal-doped $\mathrm{SrTiO}_{3}$ photocatalysts for water splitting. The Journal of Physical Chemistry C, 116(14), pp.7897-7903.

7. Huang, L., Li, R., Chong, R., Liu, G., Han, J. and Li, C., 2014. Cl- making overall water splitting possible on $\mathrm{TiO}_{2}$-based photocatalysts. Catalysis Science \& Technology, 4(9), pp.2913-2918. 